\title{
Alveolar recruitment maneuver in refractory hypoxemia and lobar atelectasis after cardiac surgery: A case report
}

\author{
Marcus Vinicius Herbst-Rodrigues ${ }^{1,4^{*}}$, Vitor Oliveira Carvalho², Ludhmila Hajjar Abrahao ${ }^{3}$, Emilia Nozawa ${ }^{1}$,
} Maria Ignez Zanetti Feltrim ${ }^{1}$ and Filomena Regina Barbosa Gomes-Galas ${ }^{3}$

\begin{abstract}
Objective: This case report describes an unusual presentation of right upper lobe atelectasis associated with refractory hypoxemia to conventional alveolar recruitment maneuvers in a patient soon after coronary artery bypass grafting surgery.

Method: Case-report.

Results: The alveolar recruitment with PEEP $=40 \mathrm{cmH}_{2} \mathrm{O}$ improved the patient's atelectasis and hypoxemia.

Conclusion: In the present report, the unusual alveolar recruitment maneuver with PEEP $40 \mathrm{cmH}_{2} \mathrm{O}$ showed to be safe and efficient to reverse refractory hypoxemia and uncommon atelectasis in a patient after cardiac surgery.
\end{abstract}

\section{Background}

The most common cardiovascular postoperative complications in cardiac surgery are related to extracorporeal circulation and its inflammatory reaction. It is well known that extracorporeal circulation affects the lungs causing alveolar edema, hypoxemia and atelectasis, which can delay extubation [1].

One strategy used to reverse the hypoxemia caused by alveolar collapse is alveolar recruitment maneuvers (ARM) [2]. Most of the times, alveolar recruitment maneuvers are performed increasing positive end-expiratory pressure on the respiratory system (PEEP) to 20 or 30 $\mathrm{cmH}_{2} \mathrm{O}$ with a satisfactory result in the correction of hypoxemia in patients soon after cardiac surgery.

This case report aims to describe an unusual presentation of right upper lobe atelectasis associated with refractory hypoxemia to conventional alveolar recruitment maneuvers in a patient soon after coronary artery bypass grafting surgery.

\footnotetext{
* Correspondence: marcus@fisiorespiratoria.com.br

${ }^{1}$ Physiotherapy Department, Heart Institute (InCor), University of Sao Paulo

Medical School, Sao Paulo, Brazil

${ }^{4}$ Av. Dr. Enéas de Carvalho Aguiar, 44. Serviço de Fisioterapia, Bloco 1, $2{ }^{\circ}$

Andar, InCor, São Paulo CEP: 05403-900, Brazil

Full list of author information is available at the end of the article
}

\section{Case report}

A 53-year-old, diabetic, male patient with ischemic cardiomyopathy (left ventricle ejection fraction of $20 \%$ ) in use of intra-aortic balloon (1:1) with normal X-Ray (Figure 1) was submitted to coronary artery bypass grafting surgery (extracorporeal circulation time of $106 \mathrm{~min}$ utes, clamping time of 61 minutes, the bypass include: left internal thoracic artery to left anterior descending artery, greater saphenous vein to diagonal branch and greater saphenous vein to obtuse marginal branch) in our hospital in July 2011.

The patient (ASA III) received midazolam orally (10 mg) administered one hour before surgery. The anesthetic technique is standardized at our institution. We used propofol for induction of anesthesia in combination with fentanyl hydrochloride. The neuromuscular blocking agent used was cisatracurium. Soon after surgery, the sedated (Ramsay 3-4) patient was referred to the intensive care unit under mechanical ventilation VIASYS $^{\mathrm{mi}}$ AVEA $^{\mathrm{Tm}}$, volume-controlled ventilation, Synchronized Intermittent Mandatory Ventilation + Pressure Support Ventilation, VCV-SIMV + PSV, of $8 \mathrm{ml} \backslash \mathrm{kg}$, total respiratory rate of 12 breaths per minute, PEEP of $5 \mathrm{cmH}_{2} \mathrm{O}, \mathrm{FiO}_{2}$ of 0.6 and $\mathrm{PSV}$ of $10 \mathrm{cmH}_{2} \mathrm{O}$ ) in infusion of dobutamine $16 \mathrm{mcg} / \mathrm{Kg} / \mathrm{min}$, noradrenaline $0.3 \mathrm{mcg} /$ $\mathrm{Kg} / \mathrm{min}$, Levosimendan $5 \mu \mathrm{g} / \mathrm{kg} / \mathrm{min}$ and intra-aortic

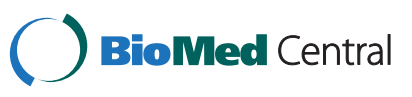




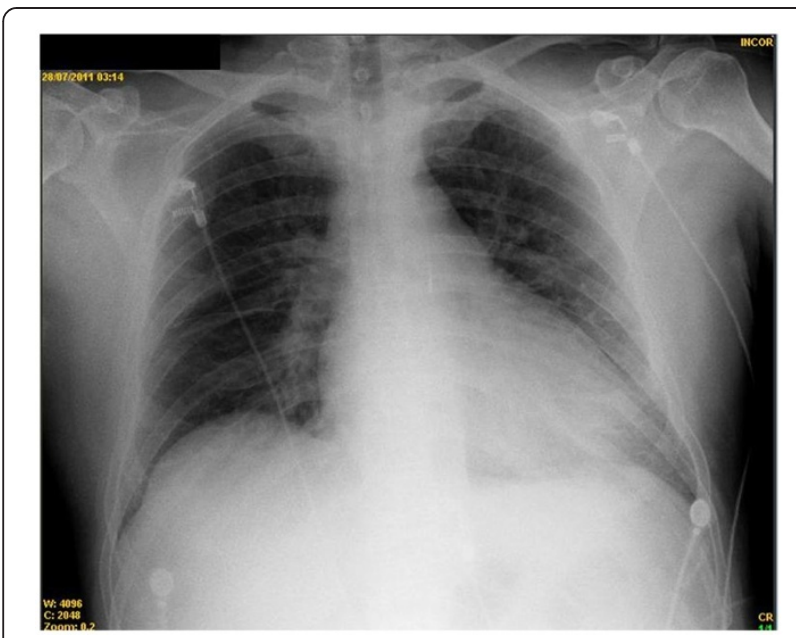

Figure 1 Pre-operative X-ray showing normal lung fields.

balloon of 1:2. Sequential blood gas analysis and biochemical tests before and after surgery are showed in Table 1.

According to the first blood gas analysis in the intensive care unit $\left(\mathrm{PaO}_{2} \mid \mathrm{FiO}_{2}<200\right)$, the patient was included in the hospital protocol for alveolar recruitment maneuver [3]. In addition, patient's X-Ray showed an unusual atelectasis in upper right lobe (Figure 2). The alveolar recruitment maneuver was performed in CPAP mode of $30 \mathrm{cmH} 2 \mathrm{O}$ and delta pressure PSV of $10 \mathrm{cmH}_{2} \mathrm{O}$, maintained for 30 seconds, followed by three consecutive maneuvers with 30 seconds of interval. This methodology is standardized in our hospital routine. Alveolar recruitment maneuver was performed increasing PEEP to $30 \mathrm{cmH}_{2} \mathrm{O}$ for 30 seconds ( 3 times) with an interval of 30 seconds between maneuvers.

After the alveolar recruitment with PEEP of $30 \mathrm{cmH}_{2} \mathrm{O}$ (peak inspiratory pressure of $40 \mathrm{cmH}_{2} \mathrm{O}$ and PSV $10 \mathrm{cmH}_{2} \mathrm{O}$ ), the patient did not show great improvement in oxygenation (Table 1). This time, our staff decided to perform a more aggressive alveolar recruitment maneuver increasing PEEP to $40 \mathrm{cmH}_{2} \mathrm{O}$ (peak inspiratory pressure of $50 \mathrm{cmH}_{2} \mathrm{O}$ ). The patient did not now show any hemodynamic alterations or pulmonary complications like pneumothorax during these alveolar recruitment maneuvers. After the alveolar recruitment with $40 \mathrm{cmH}_{2} \mathrm{O}$, the patient showed a great improvement in oxygenation and total resolution of atelectasis, as demonstrated in X-Ray (Figure 3). One hour after the recruitment maneuver, the mechanical ventilation was discontinued with success. Blood gas analysis, biochemical tests and X-Ray after extubation remained in normal values (Table 1 and Figure 4).

\section{Discussion}

In this report, the studied patient showed great improvement in oxygenation and total resolution of atelectasis after unconventional alveolar recruitment maneuver in post-operatory cardiac surgery (Table 1).

In the past decade, the PEEP therapy was used with some restrictions due to hemodynamic side effects in these kind of patients. After the study by van den Berg

Table 1 Patient's data before and after alveolar recruitment maneuver

\begin{tabular}{|c|c|c|c|c|c|c|}
\hline $\begin{array}{l}\text { Arterial blood gas } \\
\text { test }\end{array}$ & $\begin{array}{l}\text { Beginning surgery } \\
\text { (OR) }\end{array}$ & $\begin{array}{l}\text { Ending surgery } \\
\text { (OR) }\end{array}$ & Arriving ICU & $\begin{array}{l}\text { After first ARM } \\
\left(30 \mathrm{cmH}_{2} \mathrm{O}\right)\end{array}$ & $\begin{array}{l}\text { After second ARM } \\
\left(40 \mathrm{cmH}_{2} \mathrm{O}\right)\end{array}$ & $\begin{array}{l}\text { After } \\
\text { extubation }\end{array}$ \\
\hline $\mathrm{pH}$ & 7.41 & 7.38 & 7.32 & 7.39 & 7.40 & 7.38 \\
\hline $\mathrm{P}_{\mathrm{a}} \mathrm{CO}_{2}(\mathrm{mmHg})$ & 37 & 32.3 & 37.2 & 32.7 & 31.3 & 32.9 \\
\hline $\mathrm{P}_{\mathrm{a}} \mathrm{O}_{2}(\mathrm{mmHg})$ & 88.8 & 154 & 69.2 & 75.9 & 155 & 126 \\
\hline $\mathrm{P}_{\mathrm{a}} \mathrm{O}_{2} / \mathrm{FiO}_{2}$ & 148 & 250 & 115 & 126 & 258 & 315 \\
\hline $\mathrm{SatO}_{2}(\%)$ & 95.9 & 98.6 & 90.5 & 94.1 & 98.2 & 97.9 \\
\hline HCO3 (mEq/L) & 23.1 & 18.8 & 18.4 & 19.3 & 18.8 & 19.1 \\
\hline BE & -0.7 & -5.0 & -6.6 & -4.4 & -4.7 & -4.7 \\
\hline Hematocrit (\%) & 37 & 30 & 36 & 37 & 32 & 31 \\
\hline Hemoglobin $(g / d L)$ & 11.9 & 9.6 & 11.6 & 12.1 & 10.3 & 10.1 \\
\hline Sodium (mEq/L) & 137 & 131 & 133 & 135 & 137 & 137 \\
\hline Potassium (mEq/L) & 4.0 & 4.7 & 3.8 & 4.2 & 4.0 & 3.8 \\
\hline Lactate $(\mathrm{mg} / \mathrm{dL})$ & 10 & 10 & 17 & 15 & 12 & 11 \\
\hline $\begin{array}{l}\text { Respiratory rate } \\
\text { (breaths per min) }\end{array}$ & 12 & 12 & 12 & 18 & 15 & 14 \\
\hline Tidal Volume (mL) & 640 & 640 & 640 & 640 & 640 & -- \\
\hline
\end{tabular}

OR: Operation room; ICU: Intensive care unit; ARM: Alveolar recruitment maneuver; $\mathrm{P}_{a} \mathrm{CO}_{2}$ : partial pressure of carbon dioxide in arterial blood; $\mathrm{P}_{\mathrm{a}} \mathrm{O}_{2}$ : partial pressure of oxygen in arterial blood ; $\mathrm{SatO}_{2}$ : Oxygen saturation in arterial blood ;BE: base excess; 


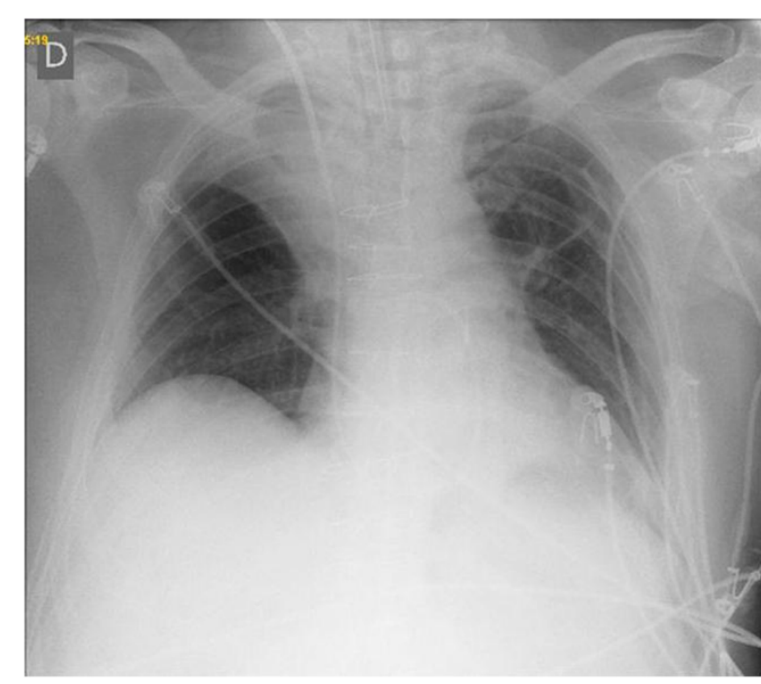

Figure 2 Unusual atelectasis in upper right lobe after cardiac surgery.

et al [4] this paradigm was changed. Airways pressures up to $20 \mathrm{cmH}_{2} \mathrm{O}$ showed minimal effects on cardiac output, primarily because of an in-phase-associated pressurization of the abdominal compartment associated with compression of the liver and squeezing of the lungs [4].

The use of alveolar recruitment maneuver with PEEP between 20 and $30 \mathrm{cmH}_{2} \mathrm{O}$ has been shown to be efficient in reversing hypoxemia after cardiac surgery [5]. Despite this, its effect in atelectasis is poorly described. In our case report, the use of $30 \mathrm{cmH}_{2} \mathrm{O}$ of PEEP was not enough to reverse hypoxemia and atelectasis after cardiac surgery. This way, we proposed the use of

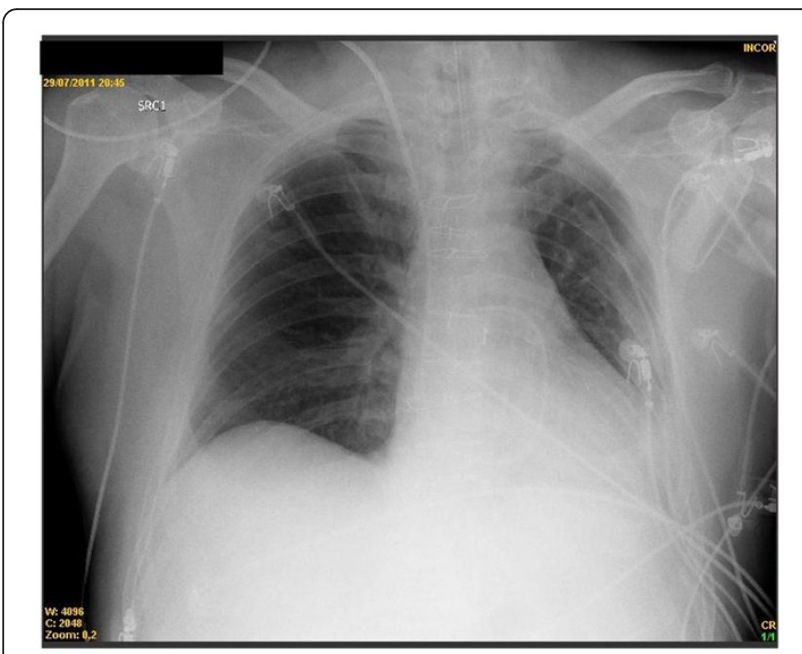

Figure 3 Total resolution of atelectasis after alveolar recruitment maneuver with $40 \mathrm{cmH}_{2} \mathrm{O}$.

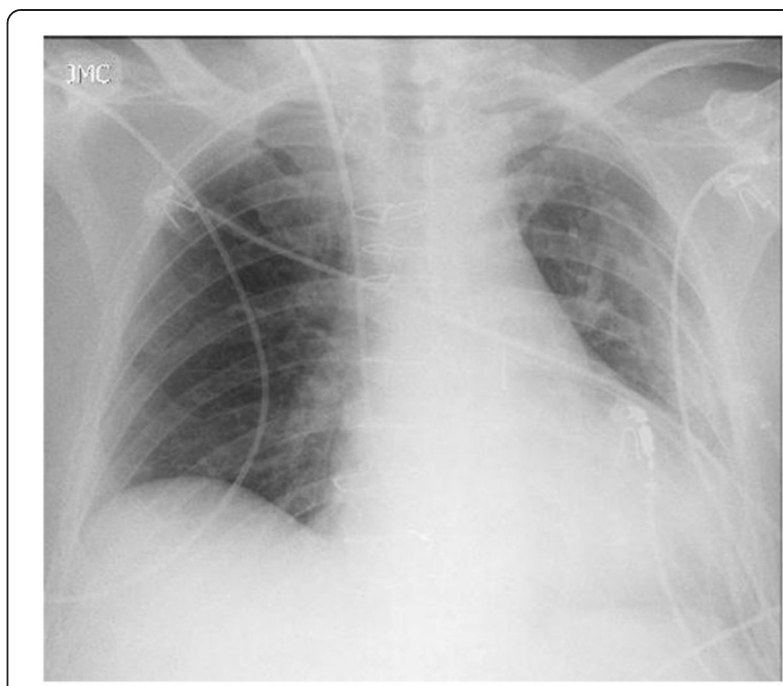

Figure 4 X-Ray after extubation remained without atelectasis.

alveolar recruitment maneveur with PEEP $40 \mathrm{cmH}_{2} \mathrm{O}$ (peak inspiratory pressure of $50 \mathrm{cmH}_{2} \mathrm{O}, \mathrm{PSV}=10$ $\mathrm{cmH}_{2} \mathrm{O}$ ) with total reversion of hypoxemia and atelectasis.

A lobar atelectasis, especially of an upper lobe, is very different from diffuse microatelecatasis, which has been extensively studied in patients with acute lung injury. Most, if not all, studies using ARM to treat "atelectasis" were actually done in patients with diffuse microatelectasis, or alveolar collapse, which is seen in dependent regions of the lungs (usually postero-inferior regions in supine patients). This difference should be the core of the discussion. The Authors should provide their interpretation as to why an ARM would be useful in this case.

In this patient, the cause of the atelectasis is unknown, but some hypotheses can be raised. The patient did not use double-lumen endotraqueal tube and selective intubation did not happen either. One possibility is mucus plugging and the other possibility is the hypoventilation during the transport of the patient, since they are manually ventilated in our service.

In unconventional situations like refractory hypoxemia associated with atelectasis, the use of alveolar recruitment maneuvers should be considered since the patient is hemodynamically stable and normovolemic. Despite this, new studies must be performed to ensure the safety and systematic indications of high levels of PEEP during alveolar recruitment maneuvers in patients after cardiac surgery.

\section{Conclusion}

In the present report, the unusual alveolar recruitment maneuver with PEEP $40 \mathrm{cmH}_{2} \mathrm{O}$ showed to be safe and 
efficient to reverse refractory hypoxemia and uncommon atelectasis in a patient after cardiac surgery.

\section{Consent}

Consent was obtained from the patient for publication of this case-report and any accompanying images.

\section{Competing interests}

The authors declare that they have no competing interests.

\section{Authors' contribution}

MVHR and VOC collected the data, MVHR and VOC wrote the manuscript and all authors discussed the case and approved the final version of the manuscript. All authors read and approved the final manuscript.

\section{Author details}

'Physiotherapy Department, Heart Institute (InCor), University of Sao Paulo Medical School, Sao Paulo, Brazil. ${ }^{2}$ Serviço de Cirurgia Cardíaca Pediátrica do Instituto do Coração do Hospital das Clínicas da Faculdade de medicina da USP (InCor-HCFMUSP), Sao Paulo, Brazil. ${ }^{3}$ Anesthesiology Division, Heart Institute (InCor), University of Sao Paulo Medical School, Sao Paulo, Brazil. ${ }^{4}$ Av. Dr. Enéas de Carvalho Aguiar, 44. Serviço de Fisioterapia, Bloco 1, $2^{\circ}$ Andar, InCor, São Paulo CEP: 05403-900, Brazil.

Received: 21 March 2012 Accepted: 29 May 2012

Published: 22 June 2012

\section{References}

1. Szeles TF, Yoshinaga EM, Alenca W, Brudniewski M, Ferreira FS, Auler JO, et al: Hypoxemia after myocardial revascularization: analysis of risk factors Rev Bras Anestesiol 2008, 58:124-136.

2. Borges JB, Okamoto VN, Matos GF, Caramez MP, Arantes PR, Barros F, et al: Reversibility of lung collapse and hypoxemia in early acute respiratory distress syndrome. Am J Respir Crit Care Med 2006, 174:268-278.

3. Auler Junior JO, Nozawa E, Toma EK, Degaki KL, Feltrim MI, Malbouisson LM: [Alveolar recruitment maneuver to reverse hypoxemia in the immediate postoperative period of cardiac surgery.]. Rev Bras Anestesiol 2007, 57:476488.

4. van den Berg PC, Jansen JR, Pinsky MR: Effect of positive pressure on venous return in volume-loaded cardiac surgical patients. J Appl Physiol 2002, 92:1223-1231.

5. Padovani $\mathrm{C}$, Cavenaghi OM: Alveolar recruitment in patients in the immediate postoperative period of cardiac surgery. Rev Bras Cir Cardiovasc 2011, 26:116-121.

Cite this article as: Herbst-Rodrigues et al:: Alveolar recruitment maneuver in refractory hypoxemia and lobar atelectasis after cardiac surgery: A case report. Journal of Cardiothoracic Surgery 2012 7:58.

\section{Submit your next manuscript to BioMed Central and take full advantage of:}

- Convenient online submission

- Thorough peer review

- No space constraints or color figure charges

- Immediate publication on acceptance

- Inclusion in PubMed, CAS, Scopus and Google Scholar

- Research which is freely available for redistribution 